\title{
Anti-Inflammatory and Anti-Obesity Activities of Aloe Vera
}

\section{Mohammad Kamil* and El TM Abdalla}

Department of Health, Zayed Complex for Herbal Research \& Traditional Medicine (ZCHRTM), HealthCare Licensing and Medical Education Division (HL\&ME), UAE

*Corresponding author: Mohammad Kamil, Department of Health, Zayed Complex for Herbal Research \& Traditional Medicine (ZCHRTM), HealthCare Licensing and Medical Education Division (HL\&ME), UAE

\begin{abstract}
Ethnopharmacological Relevance: A number of papers and reviews have been written on ethno pharmacological potential of Aloe vera $L$. [1,2] and Uses described in pharmacopoeias and in traditional systems of medicine: Aloe Vera Gel is widely used for the external treatment of minor wounds and inflammatory skin disorders [3-7]. Aloe latex is known for its laxative properties [8]. The gel is used in the treatment of minor skin irritations, including burns, bruises, and abrasions $[3,9,10]$. The gel is further used in the cosmetics industry as a hydrating ingredient in liquids, creams, sun lotions, shaving creams, lip balms, healing ointments, and face packs (3). As early as B.C. 400, the aloe vera plant and processed aloe products were being traded throughout Asia. By 700-800 AD, the Chinese "Materia Medicas" noted its medical benefits, referring to the plant as "Lu-hui" (black deposit) because of its bitter taste (Table 1). Internally, it is used for loss of appetite, in inflammation, jaundice, habitual constipation, gas formation in the stomach and leucorrhoea (foul smelling discharge from the genital tract) [10-15].
\end{abstract}

Table 1: The anti-arthritis effect of Aloe vera on rats $(n=8)$.

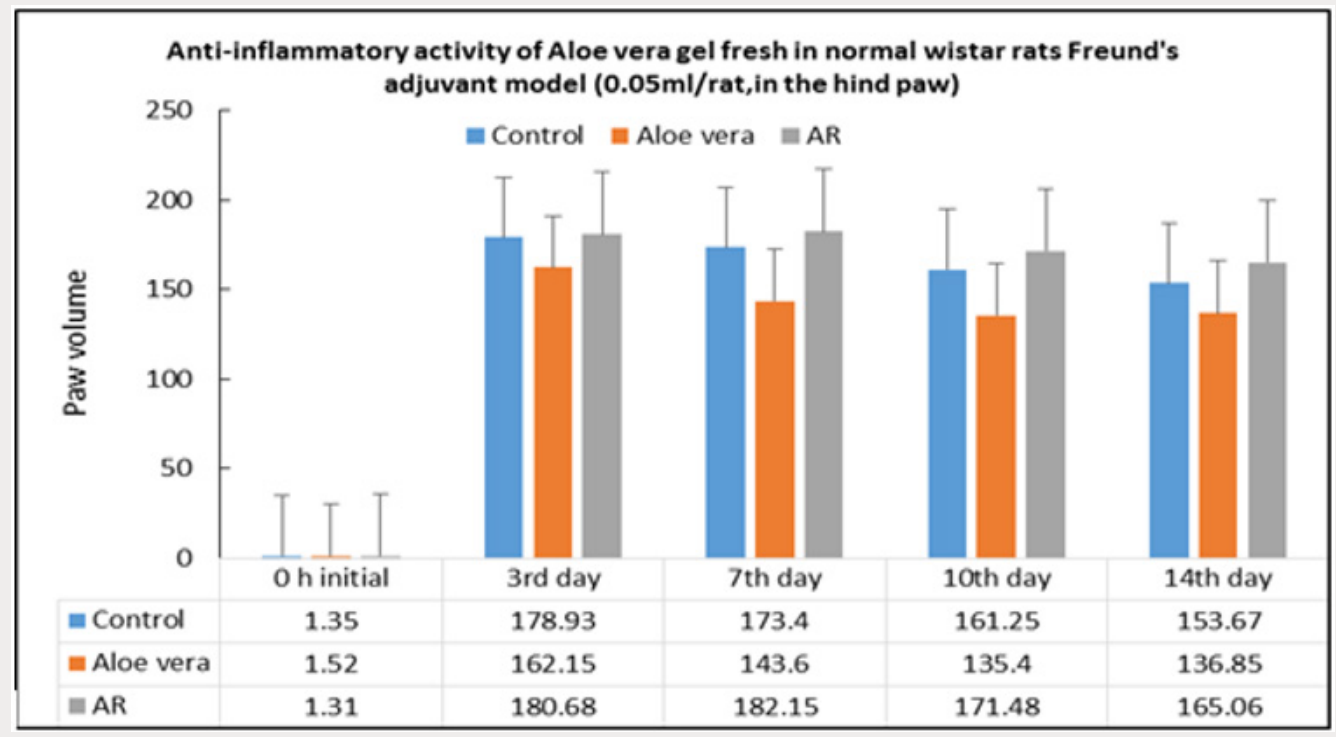

\section{Introduction}

The earliest record of a human use for Aloe vera comes from the Ebers Papyrus (an Egyptian medical record) from the $16^{\text {th }}$

century BC. According to a study published in the Indian Journal of Dermatology, in ancient Egypt, they called Aloe vera "that plant of immortality. 


\section{Description}

It is a dwarf and fleshy leaved bush. Leaves are long and spinytoothed at the margin. Red colored flowers in a bunch appear (Table
2). This plant grows well in sandy soil. In or close to mountain only, were it was planted in graveyards. Also an ornamental in towns.

Table 2: Anti-inflammatory activity of Aloe vera gel fresh in normal wistar rats carrageenan model.

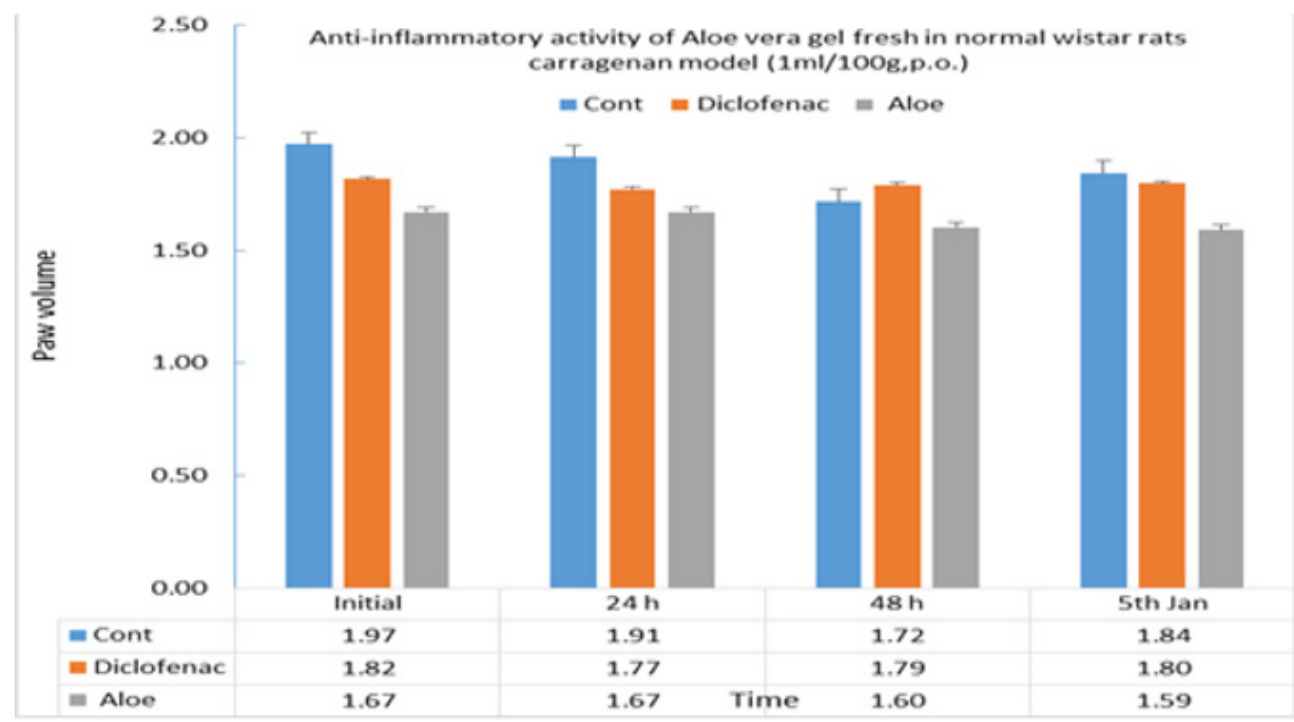

\section{Parts used}

Leaf or juice With such amazing traditional uses, Aloe vera has earned nicknames from all around the globe-names like the "silent healer", "Burn Plant", "ghai Kawar", "elephant's gall", "isha irazu”, "Cape Aloe", the "medicine plant", "Wonder plant "and the "first aid plant" (Figure 1). Aloe vera has been used for centuries is a genus that contains more than 500 species of flowering succulent plants, while there are lots of other Aloe species, none are so heavily utilized as Aloe vera (Table 3). Aloe vera has been the subject of much scientific study over the last few years, regarding several claimed therapeutic properties. The FDA approves Aloe vera as a flavoring in food supplements; it is used as cosmetics and as herbal remedies. The nutritionally dense plant also has some active compounds that may help you shed a few pounds, reduces inflammation while also improving the quality of skin and hair.

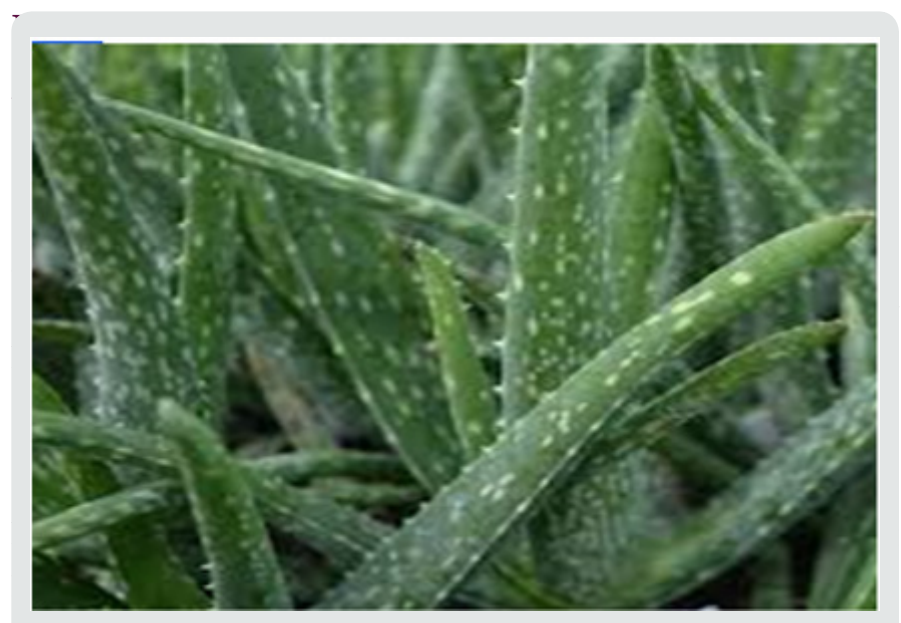

Figure 1: Leaf or juice.

Table 3: The Effects of aloe vera gel on Locomotor Activity in mice.

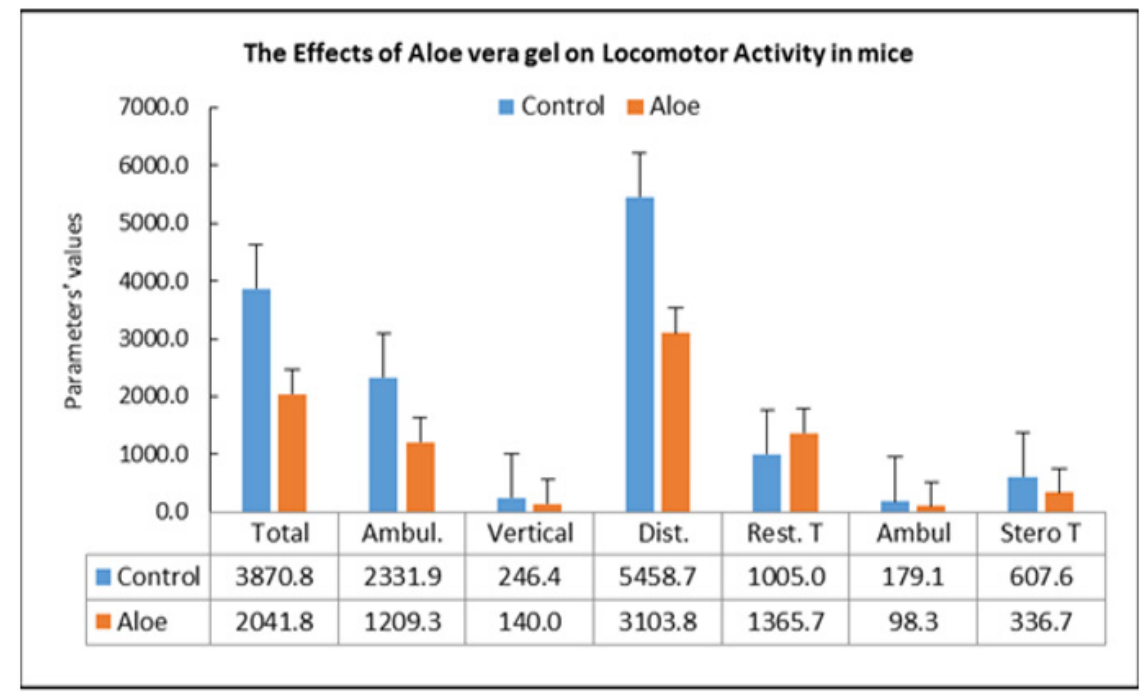

Citation: Mohammad Kamil, El TM Abdalla. Anti-Inflammatory and Anti-Obesity Activities of Aloe Vera. Open Acc J Comp \& Alt Med 2(2) - 


\section{Method}

\section{Mode of administration and doses}

In burns, the juice or the pulp of the fleshy parts of the leaf is applied externally. For sprains, the pulp or the juice may be rubbed over the affected parts two or three times (Table 4). The external skin of the leaf is removed with a knife and the fleshy pulp is made to paste using a pastel and mortar. Because of its fleshy nature, it is

Table 4: Effect of Aloe vera on mice Organ weight. slightly difficult to take out juice from the pulp. While leaf may be slightly roasted over fire, then it becomes easy to takeout juice from the pulp by squeezing through a cloth. Both pulp and juice is given in a dose of one teaspoonful ( $5 \mathrm{ml})$ three times per day, preferably on empty stomach. Since it is bitter in taste, a pinch of salt is added to it (Table 5). For children, the juice should be given by adding equal quantity of honey or small quantity of sugar in consultation with physician.

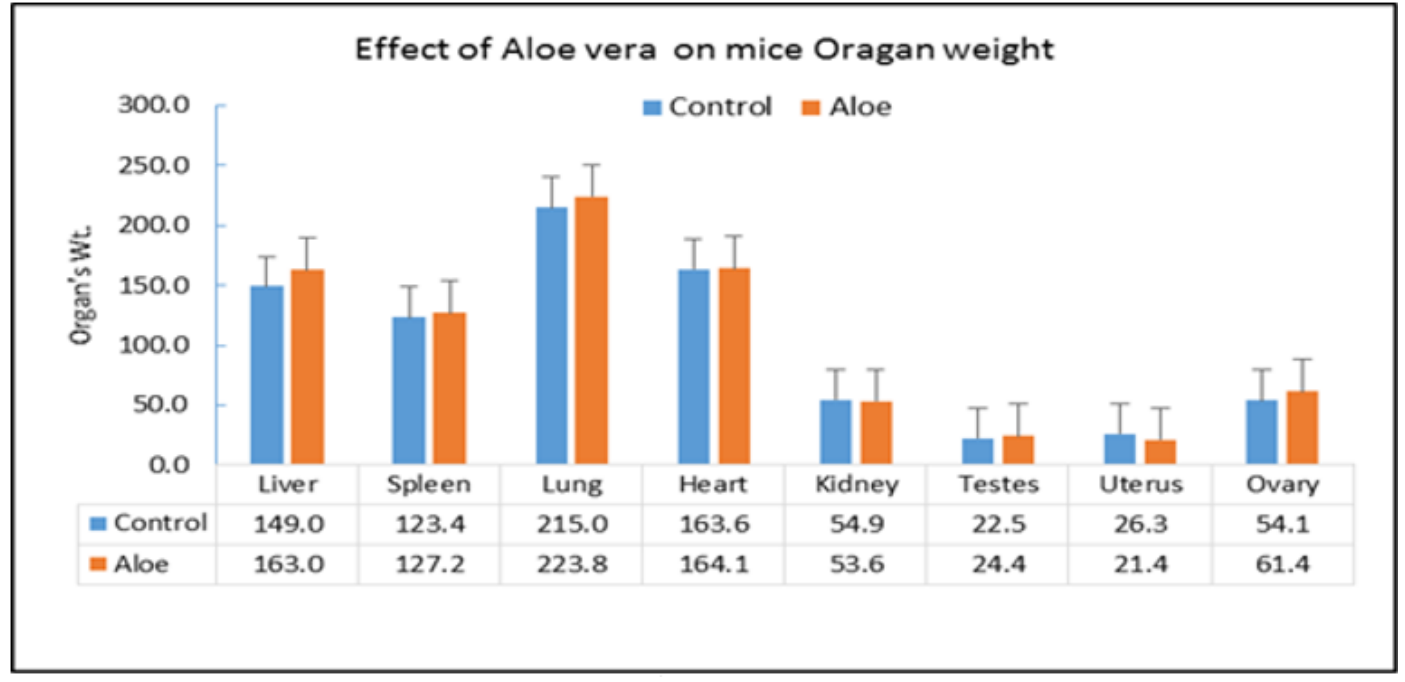

Table 5: Effect of Aloe micture antiobisty sample 0.3ml/10g BW on Haematology parameters.
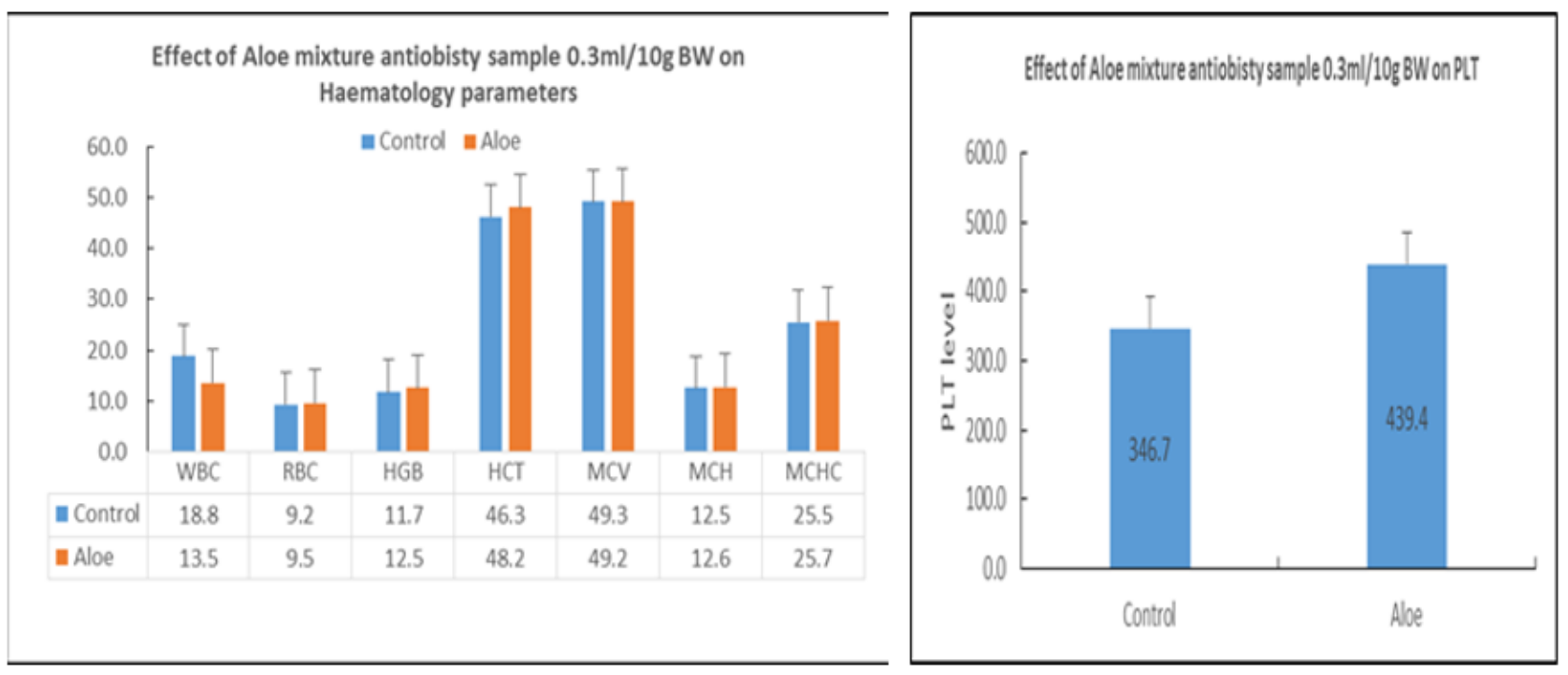

\section{Laboratory studies}

Aloe vera extract has been prepared both in water and $70 \%$ alcohol.

\section{Chemical constituents}

The following compounds are detected using Gas chromatography and Mass spectrometric (GCMS) and high performance thin layer Chromatographic (HPTLC) analyses: Anthroquinones (Up to 30\%, mainly C-glucosides). Collectively known aloin, the mixture contains barbloin. Isobarbaloin, and emodin (glycosides), and free anthroquinones (e.g. aloe-emodin). Other constituents include resins, alosin and its aglycone aloesone (a chromene):Sorbitol; Sorbic acid; Potassium sorbate; Bradykinase ; Vitamin B ; Vitamin C ;Aloin ; Benzoic acid Citric acid; Salicylic acid; $\beta$-sitosterol; Amino acids; D-Mannitol; C-glycosyl chromone; Octa decanoic acid; Hexa decanoic acid.

\section{Pharmacological studies}

To verify Aloe vera's traditional uses anti- inflammatory and anti obesity studies have been carried out in our laboratories. Anti- 
inflammatory activity (anti-arthritis activity) has been observed in rats and mouse models. Anti-inflammatory activity Dosage regime: $0.25 \mathrm{ml} /$ paw is applied topically.

Protocol: $0.10 \mathrm{ml}$ of Freund's complete adjuvant (BDH, England) is injected into the subplanter of the right hind paw. The hind paw edema is measured with plethysmometer before and $3^{\text {rd }}, 7^{\text {th }}, 10$ th to $14^{\text {th }}$ day after adjuvant is given. 5 inhibition of hind paw volume was calculated using the formula [Percentage inhibition = reading/ initial $x$ 100] of rats before and after the administration of Freund's complete adjuvant respectively in the test group and control group.

Result: there is anti-arthritis effect to paw edema induced by Freund's complete adjuvant when $0.25 \mathrm{ml} /$ paw of Aloe vera (water extract) was applied topically, but there is no effect in AR oil group.

Acute toxicity studies: The study was carried out in mice.
Both, male and female mice are used for this study. The details of the experimental protocol are as follows:

$\begin{array}{ll}\text { Animals } & : \text { Albino mice } \\ \text { Strain } & : \text { TO strain } \\ \text { Body weight } & : 25-30 \mathrm{~g} \\ \text { Dose } & : 5 \mathrm{~g} / \mathrm{kg} ; 0.3 \mathrm{ml} / 10 \mathrm{~g}, \text { p.o. }\end{array}$

Aloe mixture is given, orally at the dose $5 \mathrm{~g} / \mathrm{kg}(0.3 \mathrm{ml} / 10 \mathrm{~g}$, p.o.). The control group is given same volume of distilled water (Table 6 ). Both treated and control groups of animals were observed for gross behavioral signs and symptoms using a battery of test. Body weights, before and at $24 \mathrm{~h}$ and 7 days after administration of drug were recorded. Signs and symptoms of toxicity and mortality, if any, is recorded during this period after the administration of the drug.

Table 6: The Effect of Aloe vera on Biochemical parameters in mice.

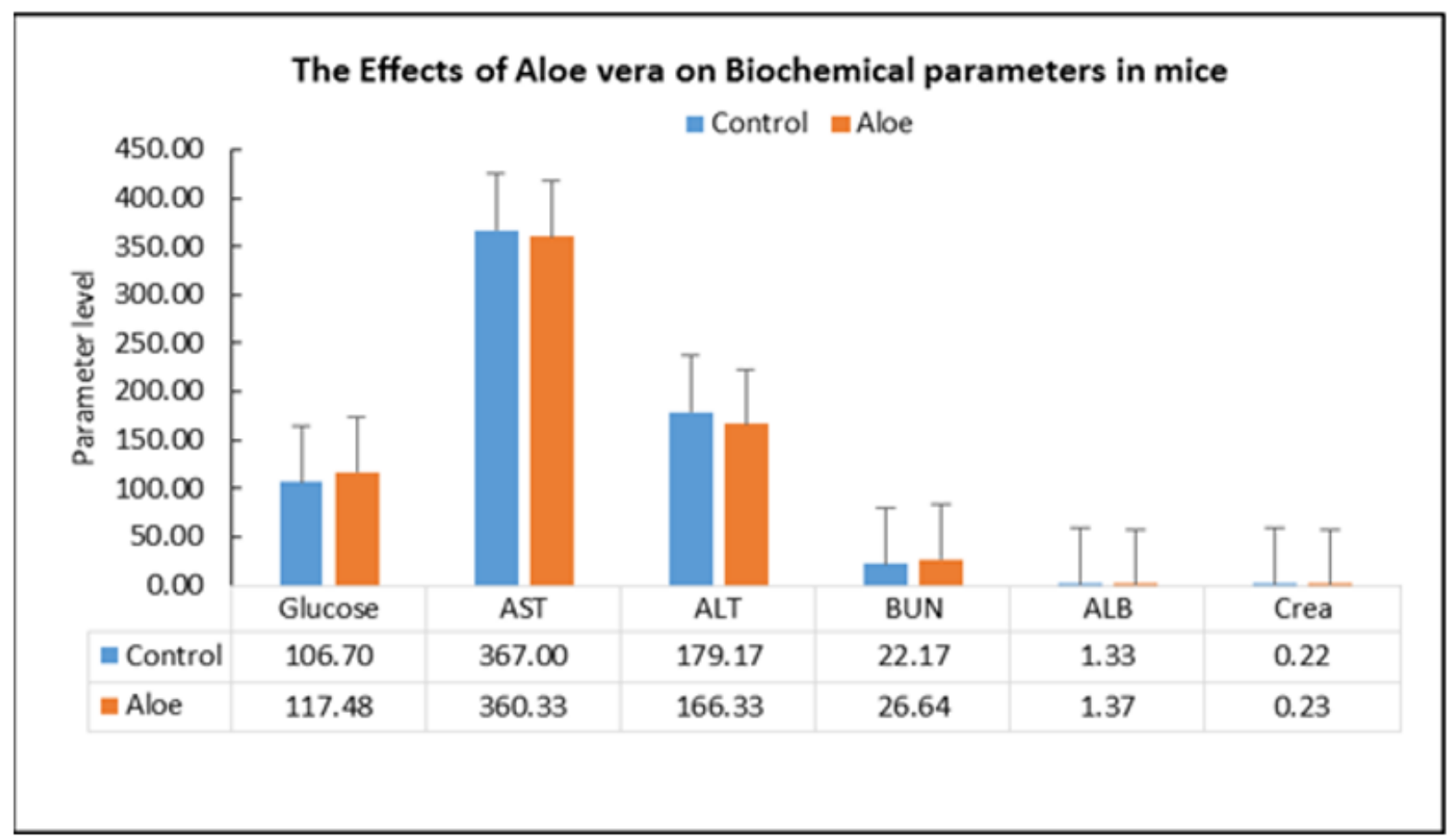

Both treated and control group of animals are observed for the following parameters: Somatic response; Coat; Postural reflex; Respiration; Piloerection; Diarrhea; Urination; Salivation; Movements; Phonation; Sensitivity to pain; Sensitivity to touch; Sensitivity to sound; Pinnal reflex; Tail rigidity; Aggression Muscle tone and in-coordination Tremors/ convulsions.

Repeated dose toxicity studies: The study was undertaken to evaluate the repeated dose effects of the Aloe mixture for 18 days treatment. Mice are divided into two groups of 10 animals each for each treatment schedule Aloe mixture $1 \mathrm{~g} / \mathrm{kg}, 0.3 \mathrm{ml} / 10 \mathrm{~g}$ ) is administered orally by gavages to the treated groups and water to control groups (Table 7). During the time course of treatment, the animals are observed for various toxic signs and symptoms. On the completion of each treatment schedule of 18 days, the blood is withdrawn and the animals are sacrificed. The body weight of animals, the organs weight ratio including, kidney, liver, spleen, heart, lung, testes and uterus were recorded. The blood was analysed for WBC, RBC, Hgb, HCT, PCV, MCV and MCHC and the serum was analysed for Cholesterol and total triglycerides. At the end of the experiment, animal vital tissues are fixed in buffered formalin for histopathological examination in case pathologic effects are needed to evaluate. During the experiment the animals were tested for locomotor activity and change in body temperature and weighed on day-1, day-2, day-14, and day-18. The weight gain during the course of treatment was calculated and statically analyzed. 
Table 7: The Effects of Aloe vera mixture on Body weight in mice.

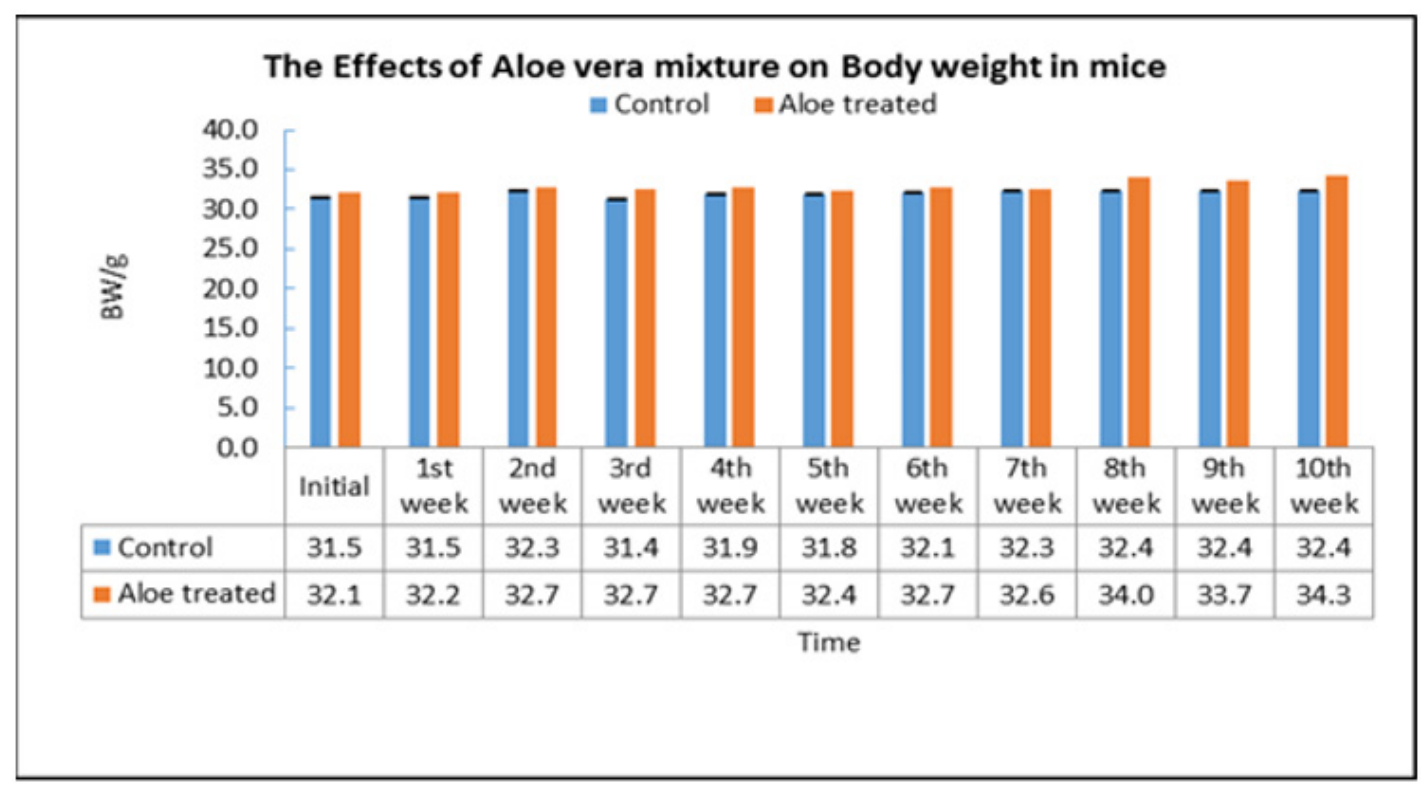

\section{Summary of Results}

a) Acute toxicity of the Aloe extract (single dose administration) studied showed no noticeable toxic signs and symptoms in the treated animals as compared to the control values.

b) The Aloe extract did not cause mortality among the treated animals, at the doses tested.

c) The repeated doses effects (18 days treatment) studies showed no significant change in locomotor activity of the animals, motor co-ordination, and body temperature of the treated animals as compared with control.

\section{Conclusion}

On acute administration, the drug showed no noticeable toxic signs and symptoms and did not cause any mortality among the treated animals at the dose of $5 \mathrm{~g} / \mathrm{kg}$. The results of the repeated doses effects (Treatment for 18 days) caused no significant change in signs and symptoms, locomotor activity, vital organ weight ratio. However, out of 10 treated animals one animal showed abnormally large size liver and spleen, obliterated heart and abnormally small size kidneys. Hematological study showed significant increase in HB \& PLT as compared to the control values [16]. The biochemical parameters did not record any changes in the animals of the treated animals as compared with control except the significant elevation of BUN. The weight change studies showed from day-1 to day-18 that the animal has lost weight as compared to the control values. A significant body weight reduction has been recorded on day-14 only. Further studies are needed for a longer period of treatment.

\section{References}

1. Shamim Hossain, ANM Mamun Rashid (2013) A review on ethnic pharmacological potential of Aloe vera L. J Intercult Ethnopharmacology 2(2): 113-120.
2. Inta A, Trisonthi P, Trisonthi C (2013) Analysis of traditional knowledge in medicinal plants used by Yuan in Thailand. J Ethnopharmacol 149(1): 344-351.

3. Bruneton J (1995) Pharmacognosy, phytochemistry, medicinal plants. Paris, Lavoisier.

4. Davis RH (1994) Anti-inflammatory and wound healing of growth substance in Aloe vera. J Am Podiatr Med Assoc 84(2): 77-81.

5. Davis RH (1994) Aloe vera, hydrocortisone, and sterol influence on wound tensile strength and anti-inflammation. J Am Podiatr Med Assoc 84(12): 614-621.

6. Heggers JP (1993) Pelley RP, Robson MC. Beneficial effects of Aloe in wound healing. Phytotherapy research 7: S48-S52.

7. McCauley R (1990) Frostbite-methods to minimize tissue loss. Postgrad Med 88(8): 67-70.

8. Davis RH (1994) Anti-inflammatory and wound healing of growth substance in Aloe vera. J Am Podiatr Med Assoc 84(2): 77-81.

9. Shelton RM (1991) Aloe vera, its chemical and therapeutic properties. Int J Dermatol 30(10): 679-683.

10. Reynolds JEF (1993) Martindale, the Extra Pharmacopoeia. (30 ${ }^{\text {th }}$ Edn.), Pharmaceutical Press, London.

11. Udupa SL, Udupa, Aland Kulkarni AL (1994) Anti-inflammatory and wound healing properties of Aloe vera Fitoterapia 65: 141-114.

12. Hörmann HP, Korting HC (1994) Evidence for the efficacy and safety of topical herbal drugs in dermtology Part 1. Anti-inflammatory agents. Phytomedicine 1(2): 161-171.

13. Visuthikosol V ( 1995) Effect of aloe vera gel to healing of burn wound a clinical and Histological study. J Med Assoc Thai 78(8): 403-409.

14. Langmead L, Makins RJ, Rampton DS (2004) Anti-inflammatory effects of Aloe vera gel in human colorectal mucosa in vitro. Aliment Pharmacol Ther 19(5): 521-527.

15. Beatriz Vázquez, Guillermo Avila, David Segura, Bruno Escalante (1996) Anti-inflammatory activity of extracts from Aloe vera gel. J Ethnopharmacol 55(1): 69-75.

16. ZCHRTM-Unpublished results. 
CC (P) This work is licensed under Creative Submit Article

DOI: 10.32474/OAJCAM.2020.02.000131

\begin{tabular}{l}
$\begin{array}{c}\text { Open Access Journal of Complementary } \\
\text { \& Alternative Medicine }\end{array}$ \\
Assets of Publishing with us \\
- Global archiving of articles \\
\hline - Immediate, unrestricted online access
\end{tabular}

